\title{
Propostas e soluções para os direitos autorais na Internet
}

André Hakime Dutra

andrehdutra@gmail.com

\begin{abstract}
RESUMO
O direito autoral na internet é matéria que muito se debate nos últimos anos, devido ao uso indiscriminado das tecnologias de informação por particulares visando a divulgação e tradução não-oficial de obras em benefício da chamada nova cultura digital. A legislação, não obstante, segue inalterada, o que dificulta o trabalho do profissional jurista diante dos novos casos que vêm surgindo.
\end{abstract}

Palavras-chave: direito autoral; internet; tradução ilegal; peer-to-peer; informática; copyleft;

\section{ABSTRACT}

The copyright on the Internet is a topic that has been much debated in recent years due to the indiscriminate use of information technologies by individuals aiming the disclosure and nonofficial translation of works to the benefit of the so called new digital culture. The legislation, nevertheless, keeps unchanged, what complicates the work of the jurist on new cases that have been arising.

Keywords: copyright; internet; illegal translation; peer-to-peer; computing; copyleft;

\section{Introdução e evolução histórica}

A ideia de se demarcar os direitos do autor sobre a obra intelectual não data de um passado remoto, pois, levando-se em consideração que antes do surgimento da imprensa, em meados do século XV, era difícil a reprodução dos originais, sendo insignificantes os números de "pirataria intelectual". Entretanto, com o surgimento da imprensa , fazia-se necessária a criação de uma regulamentação para a reprodução e tradução de obras técnico-literárias. Nesse contexto a Inglaterra foi pioneira criando o Copyright Bill, em 1710, que versava sobre o direito autoral ${ }^{1}$ e suas dependências legais e éticas. Parte desta legislação vigente em terras saxônias, só chegaria ao Brasil em $1^{\circ}$ de agosto de 1898, com a Lei $496^{2}$.

Conforme Plínio Martins Filho "O direitos autorais lidam basicamente com a imaterialidade, principal característica da propriedade intelectual. Estão presentes nas

\footnotetext{
1 DIAS, Maurício Cozer, Direito Autoral. Campinas: LZN, 2002.

2 Lei revogada, substituída pela Lei no 5.988, de 14/12/1973, que tratava da "Propriedade Literária, Científica e Artística", e agora revogada em LEI No 9.610, de 19 Fev 1998, "Lei de Direitos Autorais".
} 
produções artísticas, culturais, científicas etc." ${ }^{3}$ Entende-se, portanto que direitos autorais são os direitos inerentes ao autor que seguem a obra por um período determinado, ou seja, os direitos que o autor tem de dispor, vender e sub-rogar sobre uma criação.

São direitos morais e patrimoniais, portanto o autor e descendentes tem uma garantia legal que sua produção não será copiada sem os devidos créditos e retornos. Quanto aos direitos morais, são inalienáveis e irrenunciáveis, isso significa que ainda que um autor assine um termo autorizando que terceiro receba os créditos pela autoria, esse termo é inválido e pode o autor a qualquer tempo reivindicar seu direito.

Seguindo um princípio lógico configurar legalmente a proteção ao direito do autor garante que, embora nem toda obra tenha sido necessariamente remunerada em sua criação, o autor tenha direito a um incentivo pecuniário pelo trabalho desenvolvido de modo a estimular a produção cultural.

Neste trabalho pretende-se abordar o tema: direitos autorais sobre obras provindas do exterior e sua introdução no âmbito nacional através de um estudo do comportamento da legislação vigente ante a introdução dessa cultura estrangeira no contexto nacional por meio digital. Pelo qual é permitida a transmissão de conteúdo sem qualquer rastreamento da origem e/ou pagamento sobre os direitos dos criadores da produção intelectual. Devido ao crescente número de infrações o legislador tem, cada vez mais, buscado soluções na lei vigente, que embora aprovadas as últimas normas do campo em 1998 carece de alterações para a adequação ao contexto atual.

\section{Do direito à informação e o uso do particular}

A Lei Rouanet ${ }^{4}$, em seu artigo $1^{\circ}$, inciso I formula a seguinte norma: “Fica instituído o Programa Nacional de Apoio à Cultura (Pronac), com a finalidade de captar e canalizar recursos para o setor de modo a: I - contribuir para facilitar, a todos, os meios para o livre acesso às fontes da cultura e o pleno exercício dos direitos culturais," prioriza a divulgação da cultura com fácil acesso aos cidadãos, de modo eficaz, e a redução de custos na produção intelectual. Do mesmo modo, pode-se conjugar com o artigo 46, I da lei 9.610, conforme

\footnotetext{
${ }^{3}$ MARTINS FILHO, Plínio. Direitos autorais na Internet. vol.27 n.2 Brasília: IBICT, 1998.

4 Lei 8313/91, de 23 de Dezembro de 1991, institui o Programa Nacional de Apoio á Cultura (Pronac).
} 
alude Menezes": "Nesses casos, o direito que a sociedade tem de se manter informada se sobrepõe o direito individual do autor de autorizar ou não a menção, a fixação ou outras formas de uso de sua obra."

Quando se fala em sociedade da informação, adentrando-se nesse novo contexto de produção cultural, percebe-se que a Lei de Direitos Autorais (LDA) ${ }^{6}$ tornou-se demasiado inflexível, quando comparadas a leis de outros países como EUA, Canadá e Noruega, que permitem a cópia integral de obras para uso particular em circunstâncias especificas ${ }^{7}$. Os EUA criaram a chamada doutrina do fair use $e^{8}$, ou seja, "uso justo", seria justificação plausível para o uso de obras disponíveis na internet com fins de ensino e pesquisa, mesmo sem a autorização prévia do autor, sendo aplicável nas limitações do direito do autor ante ao direito coletivo do acesso à informação, como que cumprindo uma espécie de função social da obra.

O Brasil é um dos países com as normas de direitos autorais mais restritas, onde a publicação de uma obra tem sua garantia total assegurada por até 70 anos após a morte do seu autor. Concordando com as tendências mundiais, alavancadas pelos EUA (95 anos após a morte do autor) e União Européia (70 anos após a morte do autor), de manter longos prazos de uso do direito autoral ${ }^{8}$. Mas nem toda publicação no Brasil tem seu direito tão restringido, conforme citado por Plínio Martins Filho, "O título de publicações periódicas, inclusive jornais, é protegido até um ano após a saída de seu último número, salvo se forem anuais, caso em que esse prazo se elevará em dois anos. Isso vem acabar com a prática de registrar títulos que jamais são publicados, na espera que alguém os utilize, para em seguida tentar lucrar com a ocasião."

Originalmente esses prazos foram determinados com tal longevidade tendo em consideração que a obra demorava também um longo tempo até ter início o efetivo retorno patrimonial, o que mudou no contexto atual, onde uma música pode ser lançada sem a necessidade de um estúdio e centenas de milhares de pessoas terem seu conhecimento e comprarem o disco em poucos dias. É direito de assegurado ao autor o direito de explorar economicamente sua criação intelectual, porém prazos são necessários para que não se torne prejudicial ao desenvolvimento cultural.

\footnotetext{
5 MENEZES, Elisângela Dias. Curso de Direito Autoral. Belo Horizonte: Ed. Del Rey, 2007.

6 Lei $\mathrm{n}^{\circ}$ 9610/98, de 19 de fevereiro de 1998, institui a Lei de Direitos Autorais.

${ }^{7}$ MONCAU, Luiz Fernando. O Consumidor e o Direito Autoral. Rio de Janeiro: IDEC \& CTS da FGV, 2008.

8 SANTOS, Manuella. Direito Autoral na era digital - Impactos, controvérsias e possíveis soluções. 1. ed. São Paulo: Saraiva, 2009.
} 
Com estes mesmos princípios, surgiu a Creative Commons $^{9}$, diretriz de transmissão de informação, foi criada, em oposição aos copyright, em busca do desenvolvimento do denominado copyleft ${ }^{10}$. Este último é uma classe de legislação unificada para os meios de difusão de informações, softwares, obras digitais, ou não, e trabalhos livres que possuam permissão dos autores para o repasse e/ou edição, desde que não existam lucros diretos ou indiretos com essa prática. Uma das vantagens do uso da Creative Commons é a reconciliação da tecnologia com o direito autoral, além de incentivar a criação intelectual dá ao autor a possibilidade de ele próprio gerenciar quais os direitos quer autorizar ou vedar ao particular com referência à sua obra. Nos dizeres de Manuella Santos: "Em outras palavras, o Creative Commons possibilita o uso de obras alheias sem a violação de direitos autorais."

Não são muitos autores que abordam esse tema seja no meio social jurídico, seja no meio acadêmico, sendo portanto relevante a análise da posição do escritor Paulo Coelho apresentada na conferência "Digital, Life, Design"11", sobre a tradução para a língua russa de seu livro "O Alquimista" - disponibilizada para download em seu site oficial-, que segundo o autor, aumentou as vendas no país, de mil cópias por ano para 100 mil dois anos depois o lançamento. De acordo com ele, "quando as pessoas querem mesmo ler, elas compram o livro". Além disso, aludiu que a batalha pela preservação dos direitos autorais é "uma causa perdida" e é algo que os autores podem aproveitar para usar em seu próprio benefício.

Ainda nesse sentido deve-se assinalar que a LDA não permite a compatibilidade da sua função privada, de proteger o direito do autor, visto a mudança do pensamento social, muito menos a função social da obra, que é de garantir o interesse público à cultura.

\footnotetext{
9 “O CC tem por finalidade desenvolver licenças que possam ser usadas por qualquer pessoa ou organização, para que seus trabalhos venham a ser disponibilizados para uso, cópia, disseminação e recriação. A criação de uma rede contratual de produtores e usuários de sistemas e conteúdos permite que se compartilhem seus trabalhos pela Internet." (LIMA, Clóvis Montenegro de; SANTINI, Rose Marie. Copyleft e licenças criativas de uso de informação na sociedade da informação. Ci. Inf., Brasília, v. 37, n. 1, 2008.)

10 "O copyleft é uma relação contratual construída a partir da legislação do copyright, normalmente da mesma forma que qualquer licença tradicional de proteção dos direitos autorais entre o autor e quem o publica. São algumas cláusulas deste contrato que faz o copyleft diferente e merecedor de um nome especial." (LIMA, Clóvis Montenegro de; SANTINI, Rose Marie. Copyleft e licenças criativas de uso de informação na sociedade da informação. Ci. Inf., Brasília, v. 37, n. 1, 2008.)

${ }^{11}$ Site oficial da conferência "DLD - Digital, Life, Design Conference in Munich" com maiores informações: < http://www.dld-conference.com >. Acesso em: 18 de Junho de 2010.
} 
Outro autor a abordar o tema é Emílio Garcia Mendez"12: "Na atual etapa do desenvolvimento tecnológico, em que o acesso ao conhecimento constitui a variável decisiva e fundamental de uma existência humana digna, que constitui a finalidade última dos direitos humanos, o direito à educação não pode ser submetido a qualquer tipo de negociação, devendo ser entendido como prioridade tão absoluta quanto à abolição da escravidão ou da tortura."

Evidencia-se no art. 46 da LDA, em seu inciso II, que o uso educacional ou não comercial das obras é permitido e que a disseminação acadêmica é permitida pelo inciso VIII do aludido artigo a cópia em quaisquer obras. Esses incisos ficam mais visíveis em obras cinematográficas, quando se faz referência a livros, principalmente em breves sátiras. Outras opiniões de profissionais foram divulgadas na "Carta de São Paulo pelo Acesso aos Bens Culturais" 13 que contou com assinaturas de Gilberto Gil, Fernando Anitelli, Paulo Coelho, Paulo Lins, Ladislau Dowbor e Giuseppe Cocco.

Há nos últimos anos uma frequente inclusão de obras, sejam elas, textos, vídeo ou fonográficas, na cultura brasileira, partindo das redes Peer-to-Peer $(P 2 P)$ ou de uso comum (Torrent), de troca de arquivos e dados no formato digital à sua tradução e revisão por grupos de simpatizantes de determinado assunto.

Os referidos protocolos de transferência, com licença internacional e fabricados fora do território nacional e regulamentados por leis deste aspecto devem passar por um processo técnico de inspeção, através dos diversos meios de homologação, para adquirirem uma licença local válida.

Por conseguinte, é notável o acontecimento da violação de direitos autorais, o que as indústrias internacionais, com apreciada razão, reclamam sobre o descumprimento da legislação e conseguinte reclamação sobre perda financeira na maioria das vezes não comprovada e baseada em especulação.

\footnotetext{
${ }^{12}$ E. G. Méndez, "Origem, sentido e futuro dos direitos humanos: reflexões para uma nova agenda", Revista SUR Revista Internacional de Direitos Humanos, Vol. 1,São Paulo, Rede Universitária de Direitos Humanos, 2004, p. 12 .

13 “O Partido Pirata é um movimento que surgiu no Brasil no final de 2007 a partir da rede Internacional de Partidos Piratas, organização pela defesa ao acesso à informação, o compartilhamento do conhecimento, a transparência na gestão pública e a privacidade - direitos fundamentais que são ameaçados constantemente pelos governos e corporações para controlar e monitorar os cidadãos. Não acreditamos na "propriedade intelectual" e entendemos que sua defesa no âmbito digital implica no controle dos cidadãos e na supressão dos direitos civis e liberdades individuais fundamentais." Disponível em: < http://www.partidopirata.org/sobre >. Acesso em: 27/05/2010.
} 
O direito autoral na internet basicamente utiliza quatro grupos básicos de diretrizes: a propriedade intelectual, o direito de uso, o direito de distribuição e a exploração comercial.

A Propriedade Intelectual é o direito do autor ser considerado e citado como dono de sua criação, qualquer cópia, ainda que parcial seja considerada plágio pela lei brasileira. É um direito que não prescinde de registro, mas é necessária uma prova formal da originalidade da criação. É muito comum na internet se copiar parte dos conteúdos e ir replicando ao ponto de se perder sua autoria originária. Por isso mesmo que muitos autores aderem à Creative Commons, autorizando a cópia mediante reservas, por exemplo, autorizando apenas o direito de uso e distribuição. Nesse caso, geralmente se pede apenas a citação da fonte (nome do autor, endereço digital do site de origem, etc.).

As limitações podem ser, por exemplo, dos direitos de alteração do texto ou de uma foto, ou ainda restringir sua exploração comercial (ainda que indireta). Desse modo, a lei protege o autor para que lucros provenientes de sua exploração só sejam aos legítimos criadores ou terceiros autorizados.

O problema é que na internet é difícil realizar uma fiscalização efetiva, e ainda que se consiga muitas vezes o autor não tem o interesse, visto que não haverá lucros diretos do conteúdo.

\section{Pirataria na internet}

Na LDA atual é considerado ilegal o trabalho dos tradutores não vinculados a editoras e estúdios, detentores dos direitos autorais sobre as obras. No entanto não se leva em consideração o fato de que ${ }^{14}$ : “Quando uma lei deixa de dar conta dos anseios da população por cultura e conhecimento. Quando essa mesma lei condena práticas cotidianas e legítimas dos cidadãos na busca de seus direitos. Quando uma lei está em completo descompasso com a sociedade em que é aplicada. Nesse caso, não é a sociedade quem está errada, mas a lei. É o caso da lei 9.610/98, a LDA (lei de direito autoral) brasileira."

Conforme Elisângela Dias Menezes", “o problema não é apenas jurídico, fatores sociais também corroboram para a ocorrência da pirataria". Exemplos são o subdesenvolvimento, a pobreza, as altas taxas sobre produção cultural, ou mesmo a ganância

\footnotetext{
14 VARELLA, Guilherme. Reforma da Lei de Direito Autoral é urgente para a sociedade. Disponível em: < http://ultimainstancia.uol.com.br/colunas_ver.php?idConteudo=63715 > Acesso em: 28/05/2010.
} 
das editoras que gastam proporcionalmente muito pouco na produção de uma cópia relativo ao seu preço comercial. Conforme exemplificou Manuella Santos ${ }^{8}$ : "Sempre foi mais barato comprar um jornal do que tirar uma cópia de todo o exemplar, assim como era mais econômico comprar um disco em vinil do que tentar fazer uma cópia do disco do amigo."

O trabalho dos tradutores "ilegais" contribui para a disseminação da informação, descumprindo os dizeres legais quando outras pessoas aproveitam do conteúdo traduzido para utilização no comércio. É, assim, que surge a necessidade de um regimento para controlá-los legalmente, exigindo a fiscalização, pagamentos devidos aos autores e titulares dos direitos, e a possível descriminalização desta prática.

Com o advento da informática e através de redes de afinidades, tornou-se possível uma rápida tradução e revisão de artigos, de forma não-oficial. Em determinados casos, essa tradução é irregular levando a prejuízos de direitos de editoras nacionais e internacionais, gerando conflitos de interesses.

Ora, conhecida esta situação é, portanto, interessante aos acadêmicos iniciar o desenvolvimento de justa apreciação ao efetivo o qual dispende tempo neste novo meio de transformação de informação, bem como aos titulares de direitos personalíssimos e patrimoniais sobre os artigos descritos.

A esse tipo de trabalho de tradução e desenvolvimento de obras através da internet, dáse o nome "mobilização colaborativa", como alude Sérgio Amadeu Silveira": "A mobilização técnica de hackers para desenvolver softwares de modo colaborativo gerou milhares de comunidades virtuais que unidas conformam a grande comunidade dos que defendem, usam e desenvolvem software livre. Estas cybercomunidades distribuídas por quase todos os países são comunidades transnacionais e constituem um movimento políticocultural contra o modelo hegemônico de propriedade das idéias ou dos bens imateriais. Como comunidades, os laços que ligam seus integrantes não se vinculam à imagem de uma fraternidade nacional."

Então ocorre a distribuição das traduções, que são disponibilizadas para download gratuito de obras completas em texto, vídeo ou fonográficas. Os grupos de tradução nãooficiais alegam agir pelo princípio da "democratização" e "aceleração do processo de incursão

\footnotetext{
${ }^{15}$ SILVEIRA, Sergio Amadeu. A mobilização colaborativa e a teoria da propriedade do bem intangível. 2005. Tese (Doutorado)- Universidade de São Paulo, São Paulo, 2005. Disponível em: $<$ http://twiki.softwarelivre.org/bin/view/TeseSA/WebHome > Acesso em: 21 de maio de 2010.
} 
da cultura internacional no âmbito nacional", ferindo a função erga omnes de coerção da Lei $\mathrm{n}^{\circ} 10.695$ referente ao art. 184 do Código Penal Brasileiro, onde está expresso: “Art. 184. Quem vender expuser a venda, ocultar, adquirir, distribuir, tiver em depósito ou utilizar obra ou fonograma reproduzido com fraude, com a finalidade de vender, obter ganho, vantagem, proveito, lucro direto ou indireto, para si ou para outrem, será solidariamente responsável com o contra fator, nos termos dos artigos precedentes, respondendo como contra fatores o importador e o distribuidor em caso de reprodução no exterior."

De onde se entende que a cópia, ainda que integral, sem finalidade de lucros configura apenas um ilícito administrativo, podendo ser punida no âmbito civil, enquanto a cópia com finalidade, ainda que indireta, de obter vantagem será uma ofensa à lei penal.

Tal situação se dá, principalmente, pelo fato da demora, incluindo aqui fatores burocráticos, na tradução e divulgação das obras produzidas internacionalmente, o que diminui a quantidade de informação adquirida pelos acadêmicos e cidadãos brasileiros. André Müller Maciel ${ }^{16}$ explicou em sua monografia que os tradutores legais se veem obrigados a assinar com as editoras contratos de cessão dos direitos autorais sobre sua tradução (o chamado CDA - Contrato de Direito Autoral), onde transferem definitivamente ás mesmas todos os direitos patrimoniais sobre a tradução, e esse serviço na maioria das vezes é feito por empreitada.

\section{Tendências futuras}

Quando se fala em direito autoral na internet, é impossível fugir ao tema das cópias indiscriminadas, o que originalmente eram apenas de textos e notícias, culminou no início do presente século com a cópia das multimídias, quando o aplicativo Napster desenvolveu um protocolo de transmissão de músicas Peer-to-Peer (P2P), já comentado anteriormente, que de fato descumpriu diversos acordos internacionais do direito autoral, ensejando o surgimento posterior de novas ferramentas capazes de compartilhar qualquer tipo de conteúdo sem haver uma centralização em servidores.

Consequentemente criou-se uma cultura na internet de que a cópia não é ilegal se não tiver finalidade lucrativa, mas apesar de ser uma ideologia moralmente aceita, é uma cultura

\footnotetext{
${ }^{16}$ MACIEL, André Müller. Direito autoral e o direito autoral do tradutor. 1. ed. Franca, São Paulo: Faculdade de Direito de Franca, 2006.
} 
equivocada. Em contrapartida, devido ao numeroso caso, torna-se dificílimo punir um particular por efetuar o download ilegal de um arquivo protegido por direitos autorais.

Quando se compra uma música, um software, um filme, etc., você não adquire todos os direitos sobre o mesmo, lhe é transferido, geralmente, apenas o direito de uso, em termos práticos quer dizer que pode baixar o filme para assistir no celular, no computador, na televisão, mas não é concedido o direito de comercialização ou de distribuição gratuita.

Manuella $\operatorname{Santos}^{8}$ explica que a internet não é um faroeste norte-americano, uma terra de ninguém, onde tudo se pode, visto que analogamente é possível aplicar a LDA que está em vigência para todos os fins, ou seja, quaisquer infrações que possam ocorrer no mundo real e no mundo virtual, também podem ser punidas da mesma maneira.

Nem sempre a cópia sem fins lucrativos gera prejuízos aos autores, há situações que são inclusive boas para sua divulgação e aumento de vendas, como a banda inglesa Artic Monkeys $^{8}$, que divulgou seu ultimo CD gratuitamente pela internet, o que rendeu quase 120 mil cópias no primeiro dia de lançamento oficial nas lojas. Ou da banda brasileira "Os Seminovos" que lançam suas músicas de forma gratuita na Internet, o que lhes rendeu diversos shows, participação em grandes eventos no país e uma legião de fãs sem a necessidade de um estúdio ou gravadora para sua divulgação.

Tentando evitar a difusão indiscriminada de conteúdo protegido, a indústria tem utilizado novas tecnologias e padrões, de modo a facilitar o uso legal da obra. Um exemplo interessante é a iTunes Store, da Apple Co, que fez parceria com diversas gravadoras no mundo, cobrando pelo download unitário de músicas por custo pequeno (cerca de US\$1.00 cada), dando a garantia que o conteúdo é legal e não está infectado, disponível de forma segura, e muitas vezes sendo encontrado antecipadamente. A ideia deu tão certo que a Apple criou recentemente a AppStore, para seus produtos iPhone e iPad, onde é possível encontrar aplicativos que ampliam as funcionalidades, de modo a incentivar pequenos produtores de software, transferindo parte dos lucros das vendas aos desenvolvedores.

Outro exemplo é a editora Saraiva, que oferece a opção de assinatura de obras on-line, onde diversos livros de seu acervo jurídico está disponível em formato digital, e o usuário adquire o acesso total por um ano. Essa sistemática já é utilizada por outros sites internacionais, como a Amazon. 
Quanto a filmes, o melhor exemplo é o site da rede Warner Brothers ${ }^{17}$, que disponibiliza os filmes para acesso on-line (em inglês), funcionando como se fosse uma locadora de filmes, a um baixo valor (algo em torno de US\$4.00).

\section{Propostas de melhorias}

No contexto supracitado, surge a necessidade de uma revisão na LDA que atualmente vigora, bem como a possibilidade de um acordo cultural entre as empresas e os grupos de tradução para a restituição da harmonia nos direitos autorais da sociedade da informação.

É mister indicar mudanças na legislação e jurisprudência no âmbito da violação de direitos autorais na Internet e propor melhorias na legislação vigente. Para tanto se faz necessário, a elaboração de princípios ativos que regulamentem a utilização dos serviços disponíveis na rede mundial, enquanto usuários, e no tocante ao comportamento de sites e programas de compartilhamento de informações.

De tanto, e de modo global, podemos explicitar duas diretrizes que guiem o principio da utilização deste tipo de compartilhamento de dados:

I. Estabelecer normas que regulamentem e especifiquem a utilização de transferência de arquivos á partir de redes Peer-to-Peer $(P 2 P)^{18}$.

II. Definir normas que regulamentem e especifiquem a utilização de softwares, hardwares, websites, programas ou sistemas que propiciem este tipo de troca de dados, como por exemplo, o Kindle, um dispositivo portátil desenvolvido pela empresa Amazon para a leitura de livros e revistas eletrônicas.

Assim como Manuella Santos, acreditamos que a redução dos preços certamente ajudaria a conter o volume de produtos pirateados $^{8}$, assim como a diminuição da duração do direito de exclusividade incentivaria a produção cultural no país.

Diante do conteúdo aqui exposto, propõe-se que se efetuem acordos legais entre os grupos de tradução não-oficiais e as empresas, que têm seus direitos ofendidos. A produção

\footnotetext{
${ }^{17}$ Site Oficial da loja da Warner Brothers "WBshop - The Official Online Store of Warner Bros. Studios" < http://www.wbshop.com > Acesso em 12 de Agosto de 2010.

${ }^{18}$ Peer-to-Peer "[...]rede de compartilhamento de arquivos [...], os terminais (computadores pessoais) enviam informações entre si." In GENNARI, Maria Cristina. Minidicionário de Informática. São Paulo: Saraiva. 4 Ed, 2002 (Adaptado)
} 
deste acordo poderia gerar diversos efeitos positivos dentro do âmbito econômico, tanto ao incentivo à proliferação da cultura, objetivada pela Lei Rouanet ${ }^{6}$, e propiciada pelos tradutores ilegais, quanto à geração de lucros e pagamentos de custos objetivados pelas empresas detentoras dos direitos autorais da obra. Além disso, difundiria a especialização de novos profissionais que ainda desconhecem a matéria objeto do estudo, gerando também uma tradução mais fiel aos interesses dos expectadores do artigo a ser traduzido.

Esse tipo de acordo versaria em um contrato, de cessão de direitos à tradução para grupos particulares, que enviariam seu trabalho para a empresa detentora dos direitos, a qual passaria por uma revisão final, por profissionais confiáveis, para então ser utilizado, através da Internet ou outras mídias, de maneira rápida, por exemplo, um episódio de um seriado transmitido teria cerca de dez dias para ser traduzido, revisado e enfim disponibilizado no comércio digital ou até na TV paga, ou então um livro de 400 páginas lançado em inglês, teria 2 meses para ser disponibilizado no comércio em e-book para leitores digitais, smartphones, computadores ou qualquer outro meio de portabilidade, ou 3 meses para sua primeira edição impressa.

\section{Conclusão}

A reiteração do problema supracitado mostra que a solução não está em punir os infratores, mas sim competir com eles, derrubando suas falhas. Estratificando a informação, é o que a Apple fez no iTunes Store, disponibilizando conteúdo legal e de baixo custo, com qualidade e saindo antecipadamente, há uma grande vantagem para a indústria, que continua recebendo os proventos da criação, como ao usuário, que terá segurança ao baixar o arquivo.

Do mesmo modo, a Amazon criou um dispositivo para leitura de livros eletrônicos por baixos preços (devido à desnecessidade de impressão da obra), chama-se Kindle, o que mais se destaca é o fato de incentivar o pequeno escritor, que pode ter seu livro publicado e divulgado com mais facilidade.

Porém ainda assim resta a tradução ilegal de legendas de filmes, séries e livros. Nessas situações propõe-se que a indústria aproveite os trabalhos dos grupos de tradução, criando empregos para os mesmos, incentivando a tradução colaborativa.

A indústria está se adaptando às novas tecnologias, o direito também precisa se adaptar. Percebe-se que a desburocratização na questão da portabilidade e do uso para fins de 
estudo está começando a mudar com o projeto da nova LDA $^{19}$, onde ficou claro que será permitido ao particular tirar backup ou converter conteúdo eletrônico adquirido para seu uso em outros dispositivos ou mesmo sua conservação. O que ainda resta crítica é a grande duração do prazo do direito autoral, que perdurará ainda por 70 anos após a morte do autor, o que pode significar, em alguns casos, que uma obra só caia em domínio público cerca de 100 anos após sua criação.

O que se critica não é o direito de paternidade sobre a obra, nem o direito do uso da mesma para finalidade patrimonial, mas sim a longa duração de exclusividade desse direito, ante às novas tecnologias, o que dificulta o seu acesso indiscriminado para fins educacionais e de propagação cultural.

\section{RFERÊNCIAS BIBLIOGRÁFICAS}

Consulta pública para a modernização da lei de direito autoral, Ministério da Cultura. Disponível em: < http://www.cultura.gov.br/consultadireitoautoral >. Acesso em 18 de Junho de 2010.

DIAS, Maurício Cozer, Direito Autoral. Campinas: LZN, 2002.

DLD - Digital, Life, Design Conference in Munich. (inglês) < http://www.dld-conference.com >. Acesso em: 18 de Junho de 2010.

E. G. Méndez, Origem, sentido e futuro dos direitos humanos: reflexões para uma nova agenda. Revista SUR Revista Internacional de Direitos Humanos, Vol. 1,São Paulo, Rede Universitária de Direitos Humanos, 2004, p. 12.

GENNARI, Maria Cristina. Minidicionário de Informática. São Paulo: Saraiva. 4 Ed, 2002.

LIMA, Clóvis Montenegro de; SANTINI, Rose Marie. Copyleft e licenças criativas de uso de informação na sociedade da informação. Ci. Inf., Brasília, v. 37, n. 1, 2008.

MACIEL, André Müller. Direito autoral e o direito autoral do tradutor. 1. ed. Franca, São Paulo: Faculdade de Direito de Franca, 2006.

MARTINS FILHO, Plínio. Direitos autorais na Internet. vol.27 n.2 Brasília: IBICT, 1998. MENEZES, Elisângela Dias. Curso de Direito Autoral. Belo Horizonte: Ed. Del Rey, 2007.

\footnotetext{
${ }^{19} \mathrm{O}$ projeto iniciou-se com uma consulta pública, pode ser lido na íntegra em: < http://www.cultura.gov.br/consultadireitoautoral >. Acesso em 18 de Junho de 2010.
} 
MONCAU, Luiz Fernando. O Consumidor e o Direito Autoral. Rio de Janeiro: IDEC \& CTS da FGV, 2008.

Partido Pirata. Disponível em: < http://partidopirata.org/?page_id=8 $>$. Acesso em: 27/05/2010.

SANTOS, Manuella. Direito Autoral na era digital - Impactos, controvérsias e possíveis soluções. 1. ed. São Paulo: Saraiva, 2009.

SILVEIRA, Sergio Amadeu. A mobilização colaborativa e a teoria da propriedade do bem intangível. Tese (Doutorado)- Universidade de São Paulo, São Paulo, 2005. Disponível em: $<$ http://twiki.softwarelivre.org/bin/view/TeseSA/WebHome >. Acesso em: 21 de maio de 2010.

VARELLA, Guilherme. Reforma da Lei de Direito Autoral é urgente para a sociedade. Disponível em: < http://ultimainstancia.uol.com.br/colunas_ver.php?idConteudo=63715 > Acesso em: 28/05/2010.

WBshop - The Official Online Store of Warner Bros. Studios. < http://www.wbshop.com > Acesso em 12 de Agosto de 2010. 